\title{
Genetic loci determining potato starch yield and granule morphology revealed by genome-wide association study (GWAS)
}

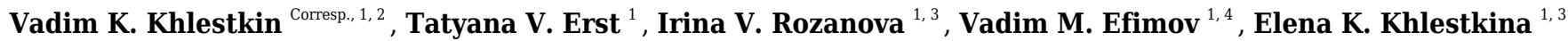 \\ 1 The Federal Research Center Institute of Cytology and Genetics SB RAS, Novosibirsk, Russia \\ 2 Russian Research Institute of Farm Animal Genetics and Breeding - Branch of the L.K. Ernst Federal Science Center of Animal Husbandry, Saint- \\ Petersburg, Russia \\ 3 The N.I. Vavilov Federal Research Center All-Russian Institute of Plant Genetic Resources (VIR), Saint-Petersburg, Russia \\ 4 Novosibirsk State University, Novosibirsk, Russia \\ Corresponding Author: Vadim K. Khlestkin \\ Email address: dir2645@yandex.ru
}

Background. It is well-documented that (bio)chemical reaction capacity of raw potato starch depends on crystallinity, morphology and other chemical and physical properties of starch granules, and these properties are closely related to gene functions. Preparative yield, amylose/amylopectin content, and phosphorylation of potato tuber starch are starch-related traits studied at the genetic level. In this paper, we perform a genome-wide association study using a 22K SNP potato array to identify for the first time genomic regions associated with starch granule morphology and to increase number of known genome loci associated with potato starch yield.

Methods. A set of 90 potato (Solanum tuberosum L.) varieties from the ICG "GenAgro" collection (Novosibirsk, Russia) was harvested, 90 samples of raw tuber starch were obtained, and DNA samples were isolated from the skin of the tubers. Morphology of potato tuber starch granules was evaluated by optical microscopy and subsequent computer image analysis. A set of 15,214 scorable SNPs was used for the genome-wide analysis. In total, 53 SNPs were found to be significantly associated with potato starch morphology traits (aspect ratio, roundness, circularity, and the $1^{\text {st }}$ bicomponent) and starch yield-related traits.

Results. A total of 53 novel SNPs was identified on potato chromosomes 1, 2, 4, 5, 6, 7, 9, 11, and 12; these SNPs are associated with tuber starch preparative yield and granule morphology. Eight SNPs are situated close to each other on the chromosome 1 and nineteen SNPs - on the chromosome 2, forming two DNA regions - potential QTLs, regulating Aspect ratio and Roundness of the starch granules. Thirtyseven of 53 SNPs are located in protein-coding regions. There are indications that granule shape may depend on starch phosphorylation processes. The GWD gene, which is known to regulate starch phosphorylation - dephosphorylation, participates in the regulation of a number of morphological traits, rather than one specific trait. Some significant SNPs are associated with membrane and plastid proteins, as well as DNA transcription and binding regulators. Other SNPs are related to low-molecular-weight metabolite synthesis, and may be associated with flavonoid biosynthesis and circadian rhythm-related metabolic processes. The preparative yield of tuber starch is a polygenic trait that is associated with a number of SNPs from various regions and chromosomes in the potato genome. 
1 Genetic loci determining potato starch yield and

2 granule morphology revealed by genome-wide

3 association study (GWAS)

4

5

6

7

8

9

10

Vadim K. Khlestkin ${ }^{1,2}$, Tatyana V. Erst ${ }^{1}$, Irina V. Rozanova ${ }^{1,3}$, Vadim M. Efimov ${ }^{1,4}$, Elena K. Khlestkina ${ }^{1,3}$

${ }^{1}$ The Federal Research Center Institute of Cytology and Genetics SB RAS, Novosibirsk, Russia ${ }^{2}$ Russian Research Institute of Farm Animal Genetics and Breeding - Branch of the L.K. Ernst Federal Science Center of Animal Husbandry, Saint-Petersburg, Russia

${ }^{3}$ The N.I. Vavilov Federal Research Center All-Russian Institute of Plant Genetic Resources (VIR), Saint-Petersburg, Russia

${ }^{4}$ Novosibirsk State University, Novosibirsk, Russia

Corresponding Author:

Vadim Khlestkin ${ }^{1}$

Prosp. Lavrent'eva, 10, Novosibirsk, 630090, Russia

Email address: khlestkin@bionet.nsc.ru

\section{Abstract}

Background. It is well-documented that (bio)chemical reaction capacity of raw potato starch depends on crystallinity, morphology and other chemical and physical properties of starch granules, and these properties are closely related to gene functions. Preparative yield, amylose/amylopectin content, and phosphorylation of potato tuber starch are starch-related traits studied at the genetic level. In this paper, we perform a genome-wide association study using a 22K SNP potato array to identify for the first time genomic regions associated with starch granule morphology and to increase number of known genome loci associated with potato starch yield.

Methods. A set of 90 potato (Solanum tuberosum L.) varieties from the ICG "GenAgro" collection (Novosibirsk, Russia) was harvested, 90 samples of raw tuber starch were obtained, and DNA samples were isolated from the skin of the tubers. Morphology of potato tuber starch 
34 granules was evaluated by optical microscopy and subsequent computer image analysis. A set

35 of 15,214 scorable SNPs was used for the genome-wide analysis. In total, 53 SNPs were found

36 to be significantly associated with potato starch morphology traits (aspect ratio, roundness,

37 circularity, and the $1^{\text {st }}$ bicomponent) and starch yield-related traits.

38 Results. A total of 53 novel SNPs was identified on potato chromosomes 1, 2, 4, 5, 6, 7, 9, 11,

39 and 12; these SNPs are associated with tuber starch preparative yield and granule morphology.

40 Eight SNPs are situated close to each other on the chromosome 1 and nineteen SNPs - on the

41 chromosome 2, forming two DNA regions - potential QTLs, regulating Aspect ratio and

42 Roundness of the starch granules. Thirty-seven of 53 SNPs are located in protein-coding

43 regions. There are indications that granule shape may depend on starch phosphorylation

44 processes. The GWD gene, which is known to regulate starch phosphorylation -

45 dephosphorylation, participates in the regulation of a number of morphological traits, rather than

46 one specific trait. Some significant SNPs are associated with membrane and plastid proteins, as

47 well as DNA transcription and binding regulators. Other SNPs are related to low-molecular-

48 weight metabolite synthesis, and may be associated with flavonoid biosynthesis and circadian

49 rhythm-related metabolic processes. The preparative yield of tuber starch is a polygenic trait

50 that is associated with a number of SNPs from various regions and chromosomes in the potato

51 genome. 
52

\section{Introduction}

54 Starch is one of the most important renewable and economically notable organic resources of humankind [1]. Simplicity of potato growing and ease of industrial production of pure potato starch makes it a necessary component and starting compound in food and chemical industries and determines valuability of an exhaustive study of all aspects of manufacturing and commercial application of potato starch is necessary. There are many publications related to chemical and biochemical transformations of starch of diverse botanical origin and differences properties of various starches. Surprisingly, little attention is paid to difference in starch properties at the level of different cultivars, such as potato cultivars. Commercial starch is still subdivided as "potato starch", "rice starch", "corn starch", and so on, despite it is well-known that there are significant differences in the properties of starch of the same botanical origin. From general considerations, it is evident that chemical and biochemical reaction ability of the raw potato starch must depend on its granules crystallinity and morphology. If so, starches from different potato varieties with different granules' properties should fit different applications better.

(Bio)chemical reaction capacity of raw potato starch depends on the crystallinity, morphology and other chemical and physical properties of starch granules. For example, after chemical acylation of the raw potato starch and fractionation of resulting acetylated starch according to granule size, amylose and amylopectin may be isolated and characterized by degree of substitution (DS) and degradability with $\alpha$-amylase, $\beta$-amylase and amyloglucosidase. In contrast

72 to amylose, the DS of the amylopectin from the differently sized granules increased with decreasing granule size. The acetyl groups of the amylose molecules from small granules are more heterogeneously distributed and located more closely to the non-reducing ends compared to amylose from larger granules. The amylose populations from small granules of the acetylated starches were less susceptible to all the enzyme degradation reactions than the amylose from

77 the large granules, even though the DS was similar. Additionally, the acetyl group distributions 
78 were different for amylopectin from different granule size fractions. [2,3]. Some benefits of small 79 potato starch granules are summarized in European patent [4]. The large size of the potato 80 granules often hampers the utilization of potato starches, for example, in printing ink formulations, 81 wherein potato starch granules may obstruct the printing apertures. Smaller granules facilitate 82 chemical modification of the starch, since the surface-volume ratio is important for the accessibility 83 of the modifying compound to the starch chains. In textile printing, for instance, 84 carboxymethylated and roll dried potato starch of small granule size enables the production of 85 finer prints. Furthermore, in adhesives, particularly in highly concentrated bag adhesives, 86 crosslinked fine potato starches may be used as fillers and in drilling fluids, crosslinked and 87 modified fine starches are expected to reduce fluid loss. In addition, smaller granule potato 88 starches may be used as filler/structurant in soap, since this starch provides a pleasant sensation to the skin. Small granular potato starches are particularly suitable for applications in the food industry. Small granular potato starch provides such advantages as lower starch dosage level, better taste profile, and smooth but not excessively swollen granules [5]. Other practical and important properties that are sensitive to starch granule size are liquid composite viscosity [6], chemical modification and flowability [7].

It is evident that the shape of potato starch granules is closely related to genes function. Amylopectin polysaccharide is predominantly responsible for the smooth granule morphology. Even low-amylose starch granules still maintain a smooth shape, whereas starch with reduced amylopectin content (by antisense knockout of SBE and GWD genes) is associated with more oddly fissured granules [8]. The role of starch synthases and related genes (GBSS, SSI - SSIII) in potato starch granule morphology has been discussed elsewhere [9]. In general, the role of certain genes in starch biosynthesis and starch granule morphology in particular is summarized 101 in the review [10].

102 Traditionally, the preparative yield of potato tuber starch is the only starch-related trait generally accepted as important for potato breeding. In the past decade, starch phosphorylation and 
104 amylose/amylopectin content were also added to the short list of the traits studied at the genetic

105 level by modern molecular biology methods. Thus, forward genetic tools, such as QTL analysis

$106[11,12]$ and association mapping [13], were used to reveal loci associated with potato traits. The

107 tuber starch characteristics, such as starch granular size and shape, and chemical-thermal

108 properties of 21 potato varieties were determined and associated with genetic diversity through

109 SSR markers. SSR-based cluster analysis revealed that varieties with interesting quality attributes

110 were distributed among all clusters and subclusters, suggesting that the genetic basis of analyzed

111 traits might differ among the varieties [12].

112 Recently developed 22K SNP potato array is characterized by a high average density of markers,

113 one locus per $40 \mathrm{~kb}$ (in the abovementioned studies [10-13], this value does not exceed one

114 marker per $4 \mathrm{Mbp}$ ). We used the chip to identify eight novel genomic regions on the chromosomes

$1151,4,5,7,8,10$, and 11 associated with starch phosphorylation. Some of the identified SNPs were

116 located in noncoding genomic regions [14].

117 In this paper, for the first time we perform a genome-wide association study using a 22K SNP

118 potato array to locate genomic regions associated with starch granule morphology and to

119 increase the number of known genomic loci associated with potato starch yield.

120 Materials \& Methods

121 Plant material

122 The same set of 90 potato (Solanum tuberosum L.) varieties from the ICG "GenAgro" collection

123 (Novosibirsk, Russia) described in [14] was used in this paper as well. Complete list of the

124 accessions used in the study and their origin is presented in Supplemental data S1 (Excel file).

125 All plants are grown during the period May to October 2017 in the same field in Novosibirsk

$126\left(54^{\circ} 52^{\prime} \mathrm{N}\right.$ and $\left.83^{\circ} 00^{\prime} \mathrm{E}\right)$. Seed tubers of all cultivars were planted in two rows with $0.75 \mathrm{~m}$

127 spacing and $0.3 \mathrm{~m}$ distance between the plants on the rows. In total, 10 plants were planted in 
128 the row; the length of each row was $10 \mathrm{~m}$. Each cultivar was planted in three replicates;

129 distances between the replicates' plots were $2 \mathrm{~m}$. Sowing: the first decade of May. Harvesting:

130 the 3rd decade of September. After harvesting tubers were stored for three weeks at $+4^{\circ} \mathrm{C}$

131 before starch isolation.

132 Starch isolation

133 Potato starch was isolated from tubers according to the typical procedure described elsewhere

134 (for example, see [15]).

135 DNA isolation and genotyping

136

137

138

139

140

141

142

143

144

145

146

147

148

149

150

151

DNA was isolated from tuber skin using DNeasy Plant Mini Kit (Qiagen) according to the standard procedure. A set of 15, 214 (71.7\%) scorable SNPs [14] was used for GWAS analysis. Genotyping information is available in Supplemental data S2 (Excel file). .

\section{Microscopy and image processing}

Sample preparation, microscopic image acquisition and processing were performed according to a previously developed procedure [15]. Five milligrams of raw starch were suspended in $1 \mathrm{~mL}$ of distilled water and dyed while shaking with $50 \mu \mathrm{L}$ of iodine solution. Twenty microliters of suspended dyed raw starch granules were placed on a microplate and covered with glass. At least four pictures of every sample were acquired (250-300 granules in every image) in transmitted light mode with bright-field technique. Micro images of starch granules obtained with the research optical microscope Axio Scope A1 (Carl ZEISS), objective - A-Plan 10x/0.25, CCD camera - AxioCam ICc 3, adaptor - TV 2/3"C 0.63x, software ZEN, total magnification 10 (objective) $\times 10$ (ocular) $\times 0.63$ (adaptor)

Automatic image processing and analysis were performed in the freely distributed ImageJ program. Seven morphological parameters were analyzed (Table S1, Fig. S1). 
152 Principal components and 2B PLS analysis

153 Two sets of principal components were calculated for both phenotypic morphological traits of 154 starch granules, as well as for the genotyping data for potato varieties, through the distance 155 matrix using the JACOBI 4 software package [16]. To calculate the distance matrix between the 156 potato varieties, we recoded the tetraploid potato genome from four-letter codes to numerical 157 codes, taking into account the dose of a certain allele. After the recoding, 0 was assigned to the 158 effector allele, and 1 was assigned as the non-effector allele, and their intermediate forms were 159 coded as $0.75,0.5$ and 0.25 . For example, the AAAA allele is reflected as $1, A A A G-$ as 0.75 , 160 AAGG - as 0.5, AGGG - as 0.25, and GGGG - as 0.

161 Both sets of principal components were applied as blocks for two-block partial least squares

162 (2B-PLS) analysis, where the first block related to phenotypic traits and the second block related 163 to genotypic.

164 Population structure matrix (Q-matrix) and the genotyping data were analyzed by Bayesian 165 cluster analysis in STRUCTURE v.2.3.4 [17]. Cluster analysis of the same population has been 166 previously discussed in the authors' previous paper [14].

167 Association analysis

168 Association analysis was performed with the TASSEL 5 package [18]. Four different statistical 169 models were tested to identify significant marker associations with potato starch yield and 170 granule morphology: (1) general linear model (GLM) without taking into account population 171 structure, (2) GLM using a Q-matrix of population membership (GLM+Q) taking into account the 172 population structure, (3) GLM taking into account population membership estimates derived 173 from principal components analysis (GLM + PCA), and (4) a composite approach that combines 174 both Q-matrix and the average relationship between individuals or lines (null matrix), 175 represented in TASSEL as mixed linear model (MLM). Adaptation of MLM for GWAS has been 
176 discussed in [19]. But MLM approach did not result into valuable results and no significant SNPs

177 were identified with this tool.

178 To identify significant SNPs, two corrections were used: (i) the Bonferroni correction, where the 179 significant threshold $(0.05)$ is divided by the total number of tests; in this work, the total number 180 of markers $(15,214)$ yields a threshold of $3.29 \times 10^{-6}$, and (ii) the false discovered rate (FDR) [20],

181 which was calculated for each isolate in each model. Some markers did not exceed the 182 threshold but still possessed low p-value $\left(>10^{-4}\right)$. We referred to the markers as "suggestive".

183 The percentage of random was $<10 \%$. Belonging of identified SNPs to genes and their

184 association with certain proteins were confirmed on the site https://plants.ensembl.org.

185 Results and Discussion

186

Phenotyping

187

188

190

191

192

193

194

195

196

197

Our initial study [15] on potato tuber starch granule morphology provided a reliable method for granule shape evaluation. This work also indicated that granule shape is specific for different potato varieties and represents a set of quantitative traits that may be applied in modern potato breeding for production starch best suitable for industrial processing. Thus, 90 varieties of potato were harvested in 2017, and 90 samples of raw tuber starch and related DNA were isolated.

Seven morphological parameters were automatically captured and evaluated for the 90 varieties: area (area of granule projection in microscope visible bright field), Feret's diameter, minimal Feret's diameter, aspect ratio (AR), roundness, circularity and solidity. Exact explanations and formulas for the parameters are provided in Table S1 and Fig. S1.

The preparative yield of starch was also captured. It varied significantly from $7.4 \%$ (variety Agata) to $18.8 \%$ (variety Tango) (Supplemental data S1, Excel file). 
198 The process of capturing starch micro images, treatment and evaluation were discussed in our 199 previous study [15]. For GWAS, we used average values of all the morphological parameters for 200 every cultivar.

\section{Genome-wide association study}

202 Principal components analysis and 2B PLS analysis

203 "Phenotype - genotype" covariation was calculated as a set of linear bicomponents (Table S2). It 204 was shown that the first three linear bicomponents capture $92.7 \%$ of the total covariation. All the 205 phenotypic traits studied, as well as preparative yield, correlate with the first bicomponent. The 206 second component showed correlations with morphology traits and no correlations with the 207 "preparative yield of starch". "Preparative yield of starch" is the only trait that correlates 208 significantly with the third bicomponent (Table S3). Plotting of the first and the third pairs of 209 bicomponents showed good positive correlation between genotypes and phenotypes in both planes (Fig. S2). The haplotypes most interesting for further selection are situated at the opposite corners of the plots and are highlighted by the circles (Fig. S3). Despite the close values of the "Preparative yield of starch" in varieties Udacha and Svitanok Kievsky, they are genetically highly 213 different.

214 Analysis of genotypic data gives three clusters (Fig. S4). The first and the second clusters 215 comprise single trait - preparative yield of starch and aspect ratio, respectively. All other 216 morphological traits studied formed the third cluster. Preparative yield of starch and aspect ratio 217 are opposite traits on the plate. Therefore, the breeding process for optimizing the traits should 218 be performed in opposite directions in genetic coordinates. 


\section{Quantile-quantile plots}

220 For all the traits studied, we evaluated whether the analysis of the population structure possesses

221 additional accuracy in finding significant SNPs. First, the GLM analysis data were compared in 222 the QQ-plots (quantile-quantile plots). They show that only for traits "circularity" and "Feret's 223 diameter" one may expect correct evaluation of noticeable SNPs with the GLM method. For the 224 other traits, GLM demonstrates inflation (overestimated p-values) of noticeable SNP evaluation 225 (Fig. S5).

226 The GLM+PCA model takes into account the population structure and returns results of 227 significantly higher quality (Fig. S6): calculated p-values are closer to the expected ones even in 228 the region of high values. Thus, calculated data for "Circularity" and "Area" traits are close to 229 theoretical ones, for "Solidity", "Feret's diameter" and "Minimal Feret's diameter", (-lg p)-values 230 are somewhat lower. For other traits, obtained $(-\lg p)$-values are slightly higher than expected. A 231 similar QQ correlation for the $1^{\text {st }}$ PLS bicomponent, which includes all the genotypic traits, shows 232 significant deviations from theoretical data and thus a lower quality of p-value evaluation (Fig. 233 S6).

234 To account for the population structure, the GLM+Q statistical model was applied. The model 235 worked well for "Feret's diameter", "Minimal Feret's diameter", "Circularity" and "Area" traits giving 236

a good conformity, but did not give $(-\lg p)$-value $>4$, which indicates the absence of significant 237 markers. The "Preparative tuber starch" and "Roundness" traits showed a number of false positive 238 SNPs (Fig. S7).

Table 1. Significant SNPs associated with preparative yield of starch and morphological 240 traits.

242 In total, 53 significant SNPs were associated with morphological and starch yield traits (Table 1). 
243 Recently, several genome association studies with starch granules size distribution were 244 published for maize [21], wheat [22, 23] and Japonica rice [24]. In the present study, no noticeable 245 SNPs with p-values higher than Bonferroni or FDR levels were found for average values for the 246 "Area”, "Feret's diameter", "Minimal Feret's diameter" and "Solidity" traits. This result is surprising, 247 since three of the traits are related to the starch granule size, which is expected to be genotype248 dependent. Indeed, if we apply ANOVA to the granules' sizes of 90 varieties involved in the study, 249 we see that factor "variety" clearly influences the size-related traits ("Area", "Feret's diameter" or 250 “Minimal Feret's diameter"). Building a "tree" of varieties' starch granule size identifies five clusters 251 of varieties (genotypes) with relatively close granule size, and ANOVA within the clusters enables 252 us to conclude that the size of the granules in the clusters is dependent on the genotype (Fig. 253 S8).

254 It appears that granule size is not single- or oligogenic but is a polygenic trait. To determine the 255 SNP pattern associated with this trait, analysis of $p$-values and their comparison with Bonferroni 256 or FDR levels is not sufficient, and more advanced and complicated analysis is warranted.

Preparative Tuber Starch Yield. Association of SNPs with phenotypic data for the "preparative tuber starch yield" trait revealed 10 significant SNPs when the GLM model was applied. The pvalue of one SNP exceeded the Bonferroni level, and the p-values of the other nine exceeded the FDR (Fig. 1). The SNPs were assigned to chromosomes 4, 5, 6, 7, 9, and 11.

Figure 1. Manhattan plots for "Preparative tuber starch yield" trait, A) GLM B) GLM+PCA 262 C) $\mathbf{G L M + Q . ~}$

For the "preparative tuber starch yield" trait, GLM+PCA appeared to be the best model according to the $Q Q$ plot (Fig. S6), but for the model (-lg p)-values are lower than for GLM (Fig. 1). No significant SNPs were revealed, but two SNPs on chromosomes 4 and 5 may be referred to as "suggestive". Nevertheless, the GLM+Q model confirmed a significant SNP on chromosome 4.

Some significant regions on chromosomes 4, 5, 9, and 11 were revealed with GLM and confirmed by GLM+Q (Table 1). Taking into account possible false-positive SNPs predicted by the QQ-plot, 
269 we lowered the FDR level following the suggestion of [25]. Setting the FDR level at the10.05 270 percentile of $p$-values gave a reasonable number of detectable SNPs (Table 1).

271 Aspect Ratio. The most promising results obtained for morphological traits related not to size 272 but to shape of the starch granules. GLM without population structure analysis yielded five 273 SNPs with (-Ig p)-values exceeding the Bonferroni level (Table 1, Fig. 2). All of these SNPs are 274 tightly grouped on chromosome 2, forming qualitative trait loci (QTL). Four other noticeable 275 SNPs determined by GLM have (-lg p)-values exceeding FDR level and are located on 276 chromosomes 1, 7, 11 and 12. The same three SNPs were confirmed by the GLM+PCA method 277 and are probably parts of appropriate QTLs. Belonging to QTLs increases the probability that 278 certain SNPs are associated with the trait studied.

\section{Figure 2. Manhattan plots for «Aspect Ratio» trait. A) GLM; B) GLM+PCA; C) GLM+Q.}

Roundness. Analysis of SNPs for the "Roundness" trait in detail reproduced the results obtained for the "Aspect ratio". Table 1 contains SNPs associated with the "Aspect ratio" and includes

SNPs for "Roundness" as well. Manhattan plots are highly similar for the two traits because both describe the shape of potato starch granules.

Circularity. Three SNPs associated with the "Circularity" trait were revealed by GWAS using the 285 statistical models GLM+PCA and GLM+Q (Table 1, Fig. S9).

SNPs correlated with the first phenotypic bicomponent. Since the "Preparative yield", "Area", "Circularity", "Feret's diameter", "Minimal Feret's diameter" and "Solidity" traits mutually contribute the first principal component significantly (Table S3), it was logical to analyze SNPs' associations with the first bicomponent to determine if there were any SNPs associated with all of the traits simultaneously.

291 One of the SNPs found for the first bicomponent (solcap_snp_c1_15462 on the 7th chromosome) 292 fits the SNP, which is significant for the "Circularity" trait. The "Circularity" trait contributes the first 293 bicomponent (-0.67992). The other four significant SNPs are unique and not associated with any 
294 single trait. All of these SNPs are a part of appropriate QTLs ("supported" with other SNPs with 295 lower (-lg p)-values) (Fig. S10). Genes around the SNPs may be responsible for the general starch 296 carbohydrate polymer arrangement in the starch granule.

297 No significant SNPs associated with the second and third bicomponents were revealed.

\section{SNPs and Related Genes/Proteins}

299 In total, 53 SNPs were found to be significant in the association study of the potato genotypes 300 and starch morphology/yield-related traits. (-lg p)-Values of one SNP were associated with 301 "preparative yield of starch", five SNPs - with "aspect ratio" and "roundness" traits, and one SNP 302 - with the $1^{\text {st }}$ bicomponent exceeded strict Bonferroni criteria. Nevertheless, some associated 303 SNPs overcame 0.1 and 0.05 FDR (false discovery rate) and suggestive levels. Most of the SNPs are located on the $1^{\text {st }}$ and $2^{\text {nd }}$ chromosomes, the least on chromosomes $4,5,6,7,9,11$, and 12. Thirty-seven of 53 SNPs are located in protein coding regions. Not one of the SNPs studied in this paper coincides with the ones associated with covalently bound phosphorus content in starch 307 [14] (Table S4).

\section{Preparative yield of starch}

309 Three out of four SNPs found on chromosome 4 are located in noncoding sequences and relate

310 to two different DNA regions. There are some other related SNPs with considerably lower 311 significance in these regions, indicating possible QTLs. The fourth SNP is situated in the different 312 region of the gene, coding for a DNA transcription regulator consisting of 95 amino acid residues.

313 All three SNPs found on chromosome 5 are related to the sequences coding different proteins.

314 One SNP corresponds to coiled coil protein with unclear function; two others are related to low315 molecular-weight organic metabolite conversion, specifically to the enzymes aldehyde 316 dehydrogenase and phenyl alanine lyase, which are responsible for alcohol-aldehyde equilibria 317 in the cell and for flavonoid synthesis. Taking into account SNPs that are less significant but still 318 associated with starch yield, we may speak about two trait-associated DNA regions that are 
319 potential QTLs. The significant SNP on chromosome 6 seems also be a part of a QTL and relates 320 to plastid transcriptionally active protein 16 (PTAC16), which is suspected to be involved in the 321 regulation of plastid gene expression. The significant SNP on chromosome 7 encodes the protein 322 translation factor SUI1. The significant SNP on chromosome 9 encodes a protein with unknown 323 function. A group of five SNPs located within 2855044 to 3572445 bp on chromosome 11 belongs 324 to the same QTL, and the SNPs are included in the coding regions of several proteins: DEGP10, 325 methylenetetrahydrofolate reductase, acetolactate synthase, and two proteins of unknown 326 function. In general, most of the proteins associated with potato starch preparative yield variations 327 are involved in plastid activity and low-molecular-weight metabolite biosynthesis.

328

332

333

334

335

336

\section{Aspect ratio and Roundness}

These traits are well-correlated with each other and describe the shape of starch granules in a similar way; thus, the traits are associated with the same SNPs. There is a locus on chromosome 1 containing eight SNPs in the same DNA region. Some of these proteins are related to circadian rhythm-regulating proteins. The circadian clock regulates numerous plant developmental and metabolic processes. In crop species, the circadian clock contributes significantly to plant performance and productivity and to the adaptation and geographical range over which crops can be grown. Other SNPs are related to the phosphorylation of important biochemical intermediates and plastid organization. On chromosome 2, a total of 19 significant SNPs were identified. The SNPs are narrowly situated, forming a single DNA region, a potential trait-related QTL. Most of the SNPs are located in noncoding regions or related to proteins with unknown functions. Two SNPs are related to WPP domain-associated protein-encoding genomic regions, one to plastid high chlorophyll fluorescence 136, another to pentatricopeptide repeat-containing protein, and one SNP is related to DNA binding protein. Two SNPs on chromosomes 7 and 11 were found in the genes encoding proteins with unknown functions.

\section{Circularity}


344 Only three SNPs associated with the circularity trait were identified. The first SNP is related to a 345 noncoding region of chromosome 12, the second is located on chromosome 7 in the 346 minichromosome maintenance 5 protein coding sequence, and the third is located on 347 chromosome 11 in the flavonoid 3',5'-hydroxylase-encoding region.

\section{First "phenotype" bicomponent}

349 Six SNPs were found to be associated with the first bicomponent from 2B-PLS, which is a complex 350 component comprising all of the traits studied. Thus, one SNP was the same for the 1st 351 bicomponent and Preparative yield (chromosome 7), while another SNP was the same for the 352 first bicomponent and Circularity (chromosome 5). Among the four other unique 1st bicomponent associated SNPs, two are related to the GWD gene, one of the key starch biosynthesis genes [10], which is responsible for the phosphorylation-dephosphorylation of glucans (chromosome 9).

The other two SNPs are associated with cytochrome B561 family protein (chromosome 5) and Pto-interacting protein 1 (chromosome 12).

In summary, chromosomes 1 and 2 contain important regions responsible for the roundness and aspect ratio of tuber starch granules. There are indications that granule shape may depend on circadian rhythm-related metabolic processes and starch phosphorylation processes. The GWD gene, which is known to regulate phosphorylation and dephosphorylation participates in the regulation of a whole number of morphological traits, rather than a single certain one. Nevertheless, some other mechanisms and proteins located on chromosome 2 influence the granule formation process. The preparative yield of tuber starch is probably a polygenic trait, regulated by a number of proteins that are encoded by sequences in various parts and chromosomes of the potato genome.

\section{Conclusions}

367 A genome-wide association study using a 22K SNP potato array enabled 53 novel SNPs to be

368 identified on chromosomes 1, 2, 4, 5, 6, 7, 9, 11, and 12; these SNPs are associated with tuber 369 starch preparative yield and with starch granule morphology (aspect ratio, roundness, circularity, 
370 and the $1^{\text {st }}$ bicomponent). Some of the SNPs observed in this study are located in noncoding 371 regions. The coding regions are associated with membrane and plastid proteins, DNA 372 transcription and binding regulators, low-molecular-weight metabolite synthesis as well as 373 flavonoid biosynthesis. The information on significant regions can be used to convert SNPs to 374 PCR-markers, convenient for screening breeding material in programs aimed on development of 375 potato varieties with desired starch properties. 


\section{Acknowledgements}

378 This work was supported by the Russian Foundation for Basic Research (No 17-29-08006).

379 GenAgro plant collection is supported by ICG (Project № 0324-2019-0039-C-01, AAAA-A16-

380 116061750188-4). We thank ICG collection "GenAgro" (Novosibirsk, Russia) providing potato

381 plant collection and personally Anna Safonova. We also thank the Traitgenetics $\mathrm{GmbH}$

382 (Gatersleben, Germany) for providing service on genotyping of potato cultivars using 22K Illumina 383 SNP array.

\section{References}

385 [1] Khlestkin VK, Peltek SE, Kolchanov NA. Review of direct chemical and biochemical 386 transformations of starch. Carbohydrate Polymers. 2018;181: 460-476. DOI: 387 10.1016/j.carbpol.2017.10.035.

388 [2] Chen Z, Schols H.A., Voragen A.G.J. Differently sized granules from acetylated potato and 389 sweet potato starches differ in the acetyl substitution pattern of their amylose polulations. 390 Carbohydrate Polymers. 2004;56(2) 219 - 226. doi.org/10.1016/j.carbpol.2004.02.004.

391 [3] Chen Z, Huang J, Suurs P, Schols HA, Voragen AGJ. Granule size affects the acetyl 392 substitution on amylopectin populations in potato and sweet potato starches. Carbohydrate 393 Polymers. 2005;62(4): 333-337 DOI: 10.1016/j.carbpol.2005.07.035.

394 [4] de Vetten NCMH, Heeres P. Method for modifying the size and/or morphology of starch 395 granules. 2004. EP 1473307A1. European Patent Office.

396 [5] Singh N, Kaur L. Morphological, thermal, rheological and retrogradation properties of potato 397 starch fractions varying in granule size. Journal of the Science of Food and Agriculture. 398 2004;84(10): 1241-1252. DOI: 10.1002/jsfa.1746.

399 [6] Zhou G, Willett JL, Craig CJ, Wu YV. Effect of starch granule size on viscosity of starch-filled 400 poly(hydroxy ester ether) composites. Journal of Polymers and the Environment. 2002;8(3):

401 145-150. DOI: 10.1023/A:1014829916940.

402 [7] Wang C, Tang C-H, Fu X, Huang Q, Zhang B. Granular size of potato starch affects 403 structural properties, octenylsuccinic anhydride modification and flowability. Food Chemistry. 
404

405

406

407

408

409

410

411

412

413

414

415

416

417

418

419

420

421

422

423

424

425

426

427

428

429

430

431

432

433

434

435 436 genotype data: Dominant markers and null alleles. Molecular Ecology Notes. 2007;7(4): 574437 578. DOI: 10.1111/j.1471-8286.2007.01758.x.

2016;212: 453-459. DOI: 10.1016/j.foodchem.2016.06.006.

[8] Blennow A, Hansen M, Schulz A, Jörgensen K, Donald AM, Sanderson J. The molecular deposition of transgenically modified starch in the starch granule as imaged by functional microscopy. Journal of Structural Biology. 2003;143(3): 229-241. DOI:

10.1016/j.jsb.2003.08.009.

[9] Ball SG, Morell MK. From bacterial glycogen to starch: understanding the biogenesis of the plant starch granule. Annual Review of Plant Biology. 2003;54(1): 207-233. DOI:

10.1146/annurev.arplant.54.031902.134927.

[10] Khlestkin VK, Peltek SE, Kolchanov NA. Target genes for development of potato (Solanum tuberosum L.) cultivars with desired starch properties. Sel'skokhozyaistvennaya Biologiya. 2017;52(1): 25-36. DOI: 10.15389/agrobiology.2017.1.25eng.

[11] Carreno-Quintero N, Acharjee A, Maliepaard C, Bachem CWB, Mumm R, Bouwmeester H, Visser RGF, Keurentjes JJB. Untargeted metabolic quantitative trait loci analyses reveal a relationship between primary metabolism and potato tuber quality. Plant Physiology. 2012;158(3): 1306-1318. DOI: 10.1104/pp.111.188441.

[12] Werij JS, Furrer H., van Eck HJ, Visser RGF, Bachem CWB. A limited set of starch related genes explain several interrelated traits in potato. Euphytica. 2012;186(2): 501-516. DOI: 10.1007/s10681-012-0651-y.

[13] Carpenter MA, Joyce NI, Genet RA, Cooper RD, Murray SR, Noble AD, Butler RC, Timmerman-Vaughan GM. Starch phosphorylation in potato tubers is influenced by allelic variation in the genes encoding glucan water dikinase, starch branching enzymes I and II, and starch synthase III. Frontiers in Plant Science. 2015;6: 1-13. DOI: 10.3389/fpls.2015.00143. [14] Khlestkin VK, Rozanova IV, Efimov VM, Khlestkina EK. Starch phosphorylation associated SNPs found by genome-wide association studies in the potato (Solanum tuberosum L.). BMC Genetics. 2019;20(Suppl 1). DOI: 10.1186/s12863-019-0729-9.

[15] Khlestkin VK, Erst TV. A practical guide to the starch granules' morphology study by microscopy. Vavilovskii Zhurnal Genetiki i Selektsii. 2017;21(6): 728-734. DOI: 10.18699/NJ17.290.

32 [16] Polunin DA, Shtayger IA, Efimov VM. JACOBI 4 software for multivariate analysis of 33 microarray data JACOBI. Letters of Novosibirsk State University = Vestnik Novosibirskogo 34 Gosudarstvennogo Universiteta. 2014: 90-98.

35 [17] Falush D, Stephens M, Pritchard JK. Inference of population structure using multilocus 
438 [18] Bradbury PJ, Zhang Z, Kroon DE, Casstevens TM, Ramdoss Y, Buckler ES. TASSEL:

439 Software for association mapping of complex traits in diverse samples. Bioinformatics.

440 2007;23(19): 2633-2635. DOI: 10.1093/bioinformatics/btm308.

441 [19] Zhang Z, Ersoz E, Lai CQ, Todhunter RJ, Tiwari HK, Gore MA, Bradbury PJ, Yu J, Arnett

442 DK, Ordovas JM, Buckler ES. Mixed linear model approach adapted for genome-wide

443 association studies. Nat Genet. 2010;42(4):355-60. doi: 10.1038/ng.546.

444 [20] Benjamini Y, Hochberg Y. Controlling the False Discovery Rate: a Practical and Powerful

445 Approach to Multiple Testing. Journal of the Royal Statistical Society. 1995;57(1): 289-300.

446 Available at: http://www.jstor.org/stable/2346101.

447 [21] Liu N, Zhang Z, Xue Y, Meng S, Huang Y, Li W, Huang J, Tang J. Identification of

448 Quantitative Trait Loci and Candidate Genes for Maize Starch Granule Size through Association

449 Mapping. Scientific Reports. 2018;8:14236. DOI:10.1038/s41598-018-31863-y.

450 [22] Li, J., Rasheed, A., Guo, Q., Dong, Y., Liu, J., Xia, X., Zhang, Y., He, Z. Genome-wide

451 association mapping of starch granule size distribution in common wheat, Journal of Cereal

452 Science (2017), doi: 10.1016/j.jcs.2017.08.016.

453 [23] Chia T, Chirico M, King R, Ramirez-Gonzalez R, Saccomanno B, Seung D, Simmonds J,

454 Trick M, Uauy C, Verhoeven T, Trafford K. A carbohydrate-binding protein, B-GRANULE

455 CONTENT 1, influences starch granule size distribution in a dose-dependent manner in

456 polyploid wheat. Journal of Experimental Botany, Vol. 71, No. 1 pp. 105-115, 2020.

457 doi:10.1093/jxb/erz405.

458 [24] Biselli C, Volante A, Desiderio F, Tondelli A, Gianinetti A, Finocchiaro F, Taddei F, Gazza L, 459 Sgrulletta D, Cattivelli L, Valè G. GWAS for Starch-Related Parameters in Japonica Rice 460 (Oryza sativa L.) Plants 2019, 8, 292; doi:10.3390/plants8080292.

461 [25] Chan E, Rowe H, Kliebenstein DJ. Understanding the Evolution of Defense Metabolites in 462 Arabidopsis thaliana Using Genome-wide Association Mapping. Genetics. 2010;185(3): $991-$ 463 1007. DOI: 10.1534/genetics.109.108522. 


\section{Table $\mathbf{1}$ (on next page)}

Significant SNPs associated with preparative yield of starch and morphological traits. 


\begin{tabular}{|c|c|c|c|c|c|c|c|c|c|c|}
\hline $\mathrm{N}$ & SNP & $\begin{array}{l}\text { Statistic } \\
\text { al model }\end{array}$ & $\begin{array}{l}\text { Significanc } \\
\text { e levels }\end{array}$ & $\begin{array}{l}\mathrm{Ch} \\
r\end{array}$ & Position & p-Value* & $\begin{array}{l}\text { Polymorphis } \\
\mathrm{m}\end{array}$ & QTL effect & $\begin{array}{l}\text { Heritabili } \\
\text { ty value }\end{array}$ & Trait \\
\hline \multirow[t]{3}{*}{1} & \multirow[t]{3}{*}{ PotVar0026637 } & GLM & Bonferroni & 4 & 282828 & $2.5 \mathrm{E}-06$ & $T / G$ & 25.34766 & 0.22363 & $\begin{array}{l}\text { Preparative } \\
\text { yield }\end{array}$ \\
\hline & & $\mathrm{GLM}+\mathrm{Q}$ & Bonferroni & 4 & 282828 & $2.3 \mathrm{E}-06$ & $T / G$ & 25.73074 & 0.23036 & $\begin{array}{l}\text { Preparative } \\
\text { yield }\end{array}$ \\
\hline & & $\begin{array}{l}\text { GML+PC } \\
A\end{array}$ & Suggestive & 4 & 282828 & $4.8 \mathrm{E}-05$ & $T / G$ & 18.41815 & 0.14736 & $\begin{array}{l}\text { Preparative } \\
\text { yield }\end{array}$ \\
\hline 2 & PotVar0098904 & $G L M+Q$ & FDR (0.05) & 4 & 61699989 & $2.2 \mathrm{E}-05$ & $\mathrm{~T} / \mathrm{C}$ & 20.20908 & 0.19196 & $\begin{array}{l}\text { Preparative } \\
\text { yield }\end{array}$ \\
\hline 3 & PotVar0098903 & $\mathrm{GLM}+\mathrm{Q}$ & FDR (0.05) & 4 & 61700041 & $1.8 \mathrm{E}-05$ & $A / G$ & 20.66912 & 0.19391 & $\begin{array}{l}\text { Preparative } \\
\text { yield }\end{array}$ \\
\hline \multirow[t]{2}{*}{4} & \multirow[t]{2}{*}{$\begin{array}{l}\text { solcap_snp_c2_320 } \\
42\end{array}$} & GLM & FDR (0.05) & 4 & 67130719 & $3.9 \mathrm{E}-06$ & $A / G$ & 24.29934 & 0.21832 & $\begin{array}{l}\text { Preparative } \\
\text { yield }\end{array}$ \\
\hline & & GLM+Q & FDR (0.05) & 4 & 67130719 & $4.74 \mathrm{E}-06$ & $A / G$ & 23.93846 & 0.21998 & $\begin{array}{l}\text { Preparative } \\
\text { yield }\end{array}$ \\
\hline \multirow[t]{3}{*}{5} & \multirow[t]{3}{*}{$\begin{array}{l}\text { solcap_snp_c2_520 } \\
81\end{array}$} & $\mathrm{GLM}+\mathrm{Q}$ & Suggestive & 5 & 1883165 & $3.8 \mathrm{E}-05$ & $A / G$ & 18.94988 & 0.17446 & $\begin{array}{l}\text { 1st bi- } \\
\text { component }\end{array}$ \\
\hline & & $\mathrm{GLM}+\mathrm{Q}$ & FDR (0.05) & 5 & 1883165 & $1.2 \mathrm{E}-05$ & $A / G$ & 21.68174 & 0.20465 & $\begin{array}{l}\text { Preparative } \\
\text { yield }\end{array}$ \\
\hline & & $\begin{array}{l}\text { GML+PC } \\
A\end{array}$ & Suggestive & 5 & 1883165 & $4.6 \mathrm{E}-05$ & $A / G$ & 18.57534 & 0.14972 & $\begin{array}{l}\text { Preparative } \\
\text { yield }\end{array}$ \\
\hline 6 & PotVar0034580 & GLM & FDR (0.05) & 5 & 51697927 & $2.1 \mathrm{E}-05$ & $\mathrm{~T} / \mathrm{C}$ & 19.33918 & 0.18535 & Preparative \\
\hline
\end{tabular}




\begin{tabular}{|c|c|c|c|c|c|c|c|c|c|c|}
\hline & & & & & & & & & & yield \\
\hline & & GLM+Q & FDR (0.05) & 5 & 51697927 & $2.09 \mathrm{E}-05$ & $\mathrm{~T} / \mathrm{C}$ & 20.39375 & 0.19744 & $\begin{array}{l}\text { Preparative } \\
\text { yield }\end{array}$ \\
\hline \multirow[t]{2}{*}{7} & \multirow[t]{2}{*}{$\begin{array}{l}\text { solcap_snp_c1_125 } \\
0\end{array}$} & GLM & FDR (0.05) & 5 & 51978384 & 4.94E-06 & $\mathrm{A} / \mathrm{C}$ & 23.69015 & 0.21211 & $\begin{array}{l}\text { Preparative } \\
\text { yield }\end{array}$ \\
\hline & & $\mathrm{GLM}+\mathrm{Q}$ & FDR (0.05) & 5 & 51978384 & $4.09 E-06$ & $\mathrm{~A} / \mathrm{C}$ & 24.26386 & 0.22014 & $\begin{array}{l}\text { Preparative } \\
\text { yield }\end{array}$ \\
\hline \multirow[t]{2}{*}{8} & \multirow[t]{2}{*}{$\begin{array}{l}\text { solcap_snp_c2_317 } \\
4\end{array}$} & GLM & FDR (0.05) & 6 & 4419112 & $8.6 \mathrm{E}-06$ & $A / G$ & 22.41938 & 0.20678 & $\begin{array}{l}\text { Preparative } \\
\text { yield }\end{array}$ \\
\hline & & GLM+Q & FDR (0.05) & 6 & 4419112 & $1.22 \mathrm{E}-05$ & $\mathrm{~A} / \mathrm{G}$ & 21.65385 & 0.20504 & $\begin{array}{l}\text { Preparative } \\
\text { yield }\end{array}$ \\
\hline 9 & $\begin{array}{l}\text { solcap_snp_c1_597 } \\
0\end{array}$ & $G L M+Q$ & FDR (0.05) & 7 & 54862076 & $4.9 \mathrm{E}-05$ & $\mathrm{~T} / \mathrm{G}$ & 18.32787 & 0.17771 & $\begin{array}{l}\text { Preparative } \\
\text { yield }\end{array}$ \\
\hline \multirow[t]{2}{*}{10} & \multirow[t]{2}{*}{ PotVar0012073 } & GLM & FDR (0.05) & 9 & 2679615 & $1.2 \mathrm{E}-05$ & $A / G$ & 19.87446 & 0.18596 & $\begin{array}{l}\text { Preparative } \\
\text { yield }\end{array}$ \\
\hline & & GLM+Q & FDR (0.05) & 9 & 2679615 & 1.17E-05 & $\mathrm{A} / \mathrm{G}$ & 21.73143 & 0.20345 & $\begin{array}{l}\text { Preparative } \\
\text { yield }\end{array}$ \\
\hline 11 & $\begin{array}{l}\text { solcap_snp_c2_595 } \\
7\end{array}$ & GLM+Q & FDR (0.05) & 11 & 2855044 & $5 \mathrm{E}-05$ & $A / G$ & 18.35478 & 0.18175 & $\begin{array}{l}\text { Preparative } \\
\text { yield }\end{array}$ \\
\hline \multirow[t]{2}{*}{12} & \multirow[t]{2}{*}{$\begin{array}{l}\text { solcap_snp_c2_630 } \\
9\end{array}$} & GLM & FDR (0.05) & 11 & 2979784 & $1.2 \mathrm{E}-05$ & $\mathrm{~T} / \mathrm{C}$ & 21.81045 & 0.21214 & $\begin{array}{l}\text { Preparative } \\
\text { yield }\end{array}$ \\
\hline & & GLM+Q & FDR (0.05) & 11 & 2979784 & $1.64 \mathrm{E}-05$ & $\mathrm{~T} / \mathrm{C}$ & 21.11726 & 0.20921 & $\begin{array}{l}\text { Preparative } \\
\text { yield }\end{array}$ \\
\hline 13 & PotVar0067347 & GLM & FDR (0.05) & 11 & 2973509 & $2.1 \mathrm{E}-05$ & $\mathrm{~T} / \mathrm{C}$ & 20.28743 & 0.19087 & Preparative \\
\hline
\end{tabular}




\begin{tabular}{|c|c|c|c|c|c|c|c|c|c|c|}
\hline & & & & & & & & & & yield \\
\hline & & GLM+Q & FDR (0.05) & 11 & 2973509 & $2.29 \mathrm{E}-05$ & $\mathrm{~T} / \mathrm{C}$ & 20.14393 & 0.19353 & $\begin{array}{l}\text { Preparative } \\
\text { yield }\end{array}$ \\
\hline \multirow[t]{2}{*}{14} & \multirow[t]{2}{*}{$\begin{array}{l}\text { solcap_snp_c2_628 } \\
5\end{array}$} & GLM & FDR (0.05) & 11 & 3080240 & $8.2 \mathrm{E}-06$ & $A / G$ & 22.48715 & 0.20539 & $\begin{array}{l}\text { Preparative } \\
\text { yield }\end{array}$ \\
\hline & & $\mathrm{GLM}+\mathrm{Q}$ & FDR (0.05) & 11 & 3080240 & 5.57E-06 & $A / G$ & 23.54087 & 0.21734 & $\begin{array}{l}\text { Preparative } \\
\text { yield }\end{array}$ \\
\hline \multirow[t]{2}{*}{15} & \multirow[t]{2}{*}{$\begin{array}{l}\text { solcap_snp_c2_618 } \\
5\end{array}$} & GLM & FDR (0.05) & 11 & 3572445 & $2.5 \mathrm{E}-05$ & $\mathrm{~A} / \mathrm{C}$ & 19.87485 & 0.18772 & $\begin{array}{l}\text { Preparative } \\
\text { yield }\end{array}$ \\
\hline & & $\mathrm{GLM}+\mathrm{Q}$ & FDR (0.05) & 11 & 3572445 & 3.37E-05 & $\mathrm{A} / \mathrm{C}$ & 19.23402 & 0.1859 & $\begin{array}{l}\text { Preparative } \\
\text { yield }\end{array}$ \\
\hline \multirow[t]{2}{*}{16} & \multirow[t]{2}{*}{ PotVar0120075 } & GLM+Q & FDR (0.05) & 1 & 433696 & $5.9 \mathrm{E}-05$ & $A / G$ & 17.91699 & 0.16272 & Aspect ratio \\
\hline & & GLM+Q & FDR (0.05) & 1 & 433696 & $8.1 \mathrm{E}-05$ & $A / G$ & 17.16788 & 0.15815 & Roundness \\
\hline \multirow[t]{2}{*}{17} & \multirow[t]{2}{*}{ PotVar0119973 } & GLM+Q & FDR (0.05) & 1 & 472422 & $6.7 \mathrm{E}-05$ & $\mathrm{~T} / \mathrm{C}$ & 17.60949 & 0.16041 & Aspect ratio \\
\hline & & GLM+Q & FDR (0.05) & 1 & 472422 & $2.1 \mathrm{E}-05$ & $\mathrm{~T} / \mathrm{C}$ & 20.3393 & 0.18167 & Roundness \\
\hline \multirow[t]{2}{*}{18} & \multirow[t]{2}{*}{ PotVar0119913 } & $\mathrm{GLM}+\mathrm{Q}$ & FDR (0.05) & 1 & 473487 & $6.7 \mathrm{E}-05$ & $A / G$ & 17.60949 & 0.16041 & Aspect ratio \\
\hline & & $\mathrm{GLM}+\mathrm{Q}$ & FDR (0.05) & 1 & 473487 & $2.1 \mathrm{E}-05$ & $A / G$ & 20.3393 & 0.18167 & Roundness \\
\hline \multirow[t]{2}{*}{19} & \multirow{2}{*}{$\begin{array}{l}\text { solcap_snp_c2_366 } \\
59\end{array}$} & $\mathrm{GLM}+\mathrm{Q}$ & FDR (0.05) & 1 & 532003 & $5.4 \mathrm{E}-05$ & $\mathrm{~T} / \mathrm{C}$ & 18.11193 & 0.16418 & Aspect ratio \\
\hline & & $\mathrm{GLM}+\mathrm{Q}$ & FDR (0.05) & 1 & 532003 & $7.3 \mathrm{E}-05$ & $\mathrm{~T} / \mathrm{C}$ & 17.4212 & 0.16008 & Roundness \\
\hline \multirow[t]{2}{*}{20} & \multirow{2}{*}{$\begin{array}{l}\text { solcap_snp_c2_366 } \\
64\end{array}$} & $\mathrm{GLM}+\mathrm{Q}$ & FDR $(0.05)$ & 1 & 535454 & $8.9 \mathrm{E}-05$ & $A / G$ & 16.95617 & 0.15717 & Aspect ratio \\
\hline & & $\mathrm{GLM}+\mathrm{Q}$ & FDR $(0.05)$ & 1 & 535454 & $9.6 \mathrm{E}-05$ & $A / G$ & 16.77846 & 0.1568 & Roundness \\
\hline
\end{tabular}




\begin{tabular}{|c|c|c|c|c|c|c|c|c|c|c|}
\hline \multirow[t]{2}{*}{21} & \multirow{2}{*}{$\begin{array}{l}\text { solcap_snp_c2_366 } \\
65\end{array}$} & $\mathrm{GLM}+\mathrm{Q}$ & FDR (0.05) & 1 & 536033 & $3.4 \mathrm{E}-05$ & $A / G$ & 19.20315 & 0.17223 & Aspect ratio \\
\hline & & $\mathrm{GLM}+\mathrm{Q}$ & FDR (0.05) & 1 & 536033 & 3.7E-05 & $A / G$ & 18.96398 & 0.17165 & Roundness \\
\hline \multirow[t]{2}{*}{22} & \multirow[t]{2}{*}{ PotVar0071846 } & GLM+Q & FDR (0.05) & 1 & 1155603 & $3.3 \mathrm{E}-05$ & $\mathrm{~A} / \mathrm{C}$ & 19.20053 & 0.17141 & Aspect ratio \\
\hline & & GLM+Q & FDR (0.05) & 1 & 1155603 & $2.5 \mathrm{E}-05$ & $A / C$ & 19.87454 & 0.17799 & Roundness \\
\hline \multirow[t]{3}{*}{23} & \multirow[t]{3}{*}{ PotVar0071852 } & GLM+Q & FDR (0.05) & 1 & 1155770 & $3.3 \mathrm{E}-05$ & $\mathrm{~T} / \mathrm{C}$ & 19.26069 & 0.17265 & Aspect ratio \\
\hline & & $\begin{array}{l}\text { GLM+PC } \\
A\end{array}$ & Suggestive & 1 & 1155770 & $8.8 \mathrm{E}-05$ & $\mathrm{~T} / \mathrm{C}$ & 17.02399 & 0.15571 & Aspect ratio \\
\hline & & GLM+Q & FDR (0.05) & 1 & 1155770 & $3.5 \mathrm{E}-05$ & $\mathrm{~T} / \mathrm{C}$ & 19.1343 & 0.17291 & Roundness \\
\hline \multirow[t]{2}{*}{24} & \multirow{2}{*}{$\begin{array}{l}\text { solcap_snp_c2_566 } \\
17\end{array}$} & GLM & FDR (0.05) & 2 & 4833289 & $5.5 \mathrm{E}-05$ & $A / G$ & 17.96239 & 0.16952 & Aspect ratio \\
\hline & & GLM & FDR (0.05) & 2 & 4833289 & $6.3 \mathrm{E}-05$ & $A / G$ & 17.67625 & 0.16727 & Roundness \\
\hline \multirow[t]{6}{*}{25} & \multirow{6}{*}{$\begin{array}{l}\text { solcap_snp_c1_163 } \\
79\end{array}$} & GLM & Bonferroni & 2 & 4839524 & $9.2 \mathrm{E}-07$ & $\mathrm{~T} / \mathrm{C}$ & 28.02326 & 0.24794 & Aspect ratio \\
\hline & & GLM+Q & FDR (0.05) & 2 & 4839524 & \begin{tabular}{|l|}
$5.4 \mathrm{E}-05$ \\
\end{tabular} & $\mathrm{~T} / \mathrm{C}$ & 18.17052 & 0.16451 & Aspect ratio \\
\hline & & $\begin{array}{l}\text { GLM+PC } \\
A\end{array}$ & Suggestive & 2 & 4839524 & 6.4E-05 & $\mathrm{T} / \mathrm{C}$ & 17.81461 & 0.15835 & Aspect ratio \\
\hline & & GLM & Bonferroni & 2 & 4839524 & \begin{tabular}{|c|}
$9.2 \mathrm{E}-07$ \\
\end{tabular} & $\mathrm{~T} / \mathrm{C}$ & 27.29335 & 0.24305 & Roundness \\
\hline & & $G L M+Q$ & FDR (0.05) & 2 & 4839524 & $2.8 \mathrm{E}-05$ & $\mathrm{~T} / \mathrm{C}$ & 19.73863 & 0.17492 & Roundness \\
\hline & & $\begin{array}{l}\text { GLM+PC } \\
A\end{array}$ & Suggestive & 2 & 4839524 & $3 \mathrm{E}-05$ & $\mathrm{~T} / \mathrm{C}$ & 19.58447 & 0.17361 & Roundness \\
\hline \multirow[t]{2}{*}{26} & \multirow[t]{2}{*}{ PotVar0032432 } & GLM & FDR (0.05) & 2 & 5126968 & $2.7 \mathrm{E}-05$ & $A / G$ & 19.76242 & 0.19231 & Aspect ratio \\
\hline & & GLM & FDR (0.05) & 2 & 5126968 & \begin{tabular}{|l|}
$2.7 \mathrm{E}-05$ \\
\end{tabular} & $A / G$ & 19.28304 & 0.18853 & Roundness \\
\hline 27 & PotVar0032402 & GLM & FDR (0.05) & 2 & 5128062 & $9.6 \mathrm{E}-06$ & $A / G$ & 22.14307 & 0.20476 & Aspect ratio \\
\hline
\end{tabular}




\begin{tabular}{|c|c|c|c|c|c|c|c|c|c|c|}
\hline & & GLM & FDR (0.05) & 2 & 5128062 & 9.9E-06 & $A / G$ & 22.07346 & 0.20424 & Roundness \\
\hline \multirow[t]{2}{*}{28} & \multirow{2}{*}{$\begin{array}{l}\text { solcap_snp_c2_435 } \\
3\end{array}$} & GLM & FDR (0.05) & 2 & 5158305 & \begin{tabular}{|l|}
$7.9 \mathrm{E}-06$ \\
\end{tabular} & $\mathrm{~T} / \mathrm{C}$ & 22.64938 & 0.2104 & Aspect ratio \\
\hline & & GLM & FDR (0.05) & 2 & 5158305 & 8.7E-06 & $\mathrm{T} / \mathrm{C}$ & 22.42338 & 0.20874 & Roundness \\
\hline \multirow[t]{2}{*}{29} & \multirow{2}{*}{$\begin{array}{l}\text { solcap_snp_c2_435 } \\
4\end{array}$} & GLM & FDR (0.05) & 2 & 5159301 & $2.2 \mathrm{E}-05$ & $\mathrm{~T} / \mathrm{C}$ & 20.07171 & 0.18573 & Aspect ratio \\
\hline & & GLM & FDR (0.05) & 2 & 5159301 & $2.5 \mathrm{E}-05$ & $\mathrm{~T} / \mathrm{C}$ & 19.85727 & 0.18411 & Roundness \\
\hline \multirow[t]{2}{*}{30} & \multirow[t]{2}{*}{ PotVar0032114 } & GLM & FDR (0.05) & 2 & 5159377 & \begin{tabular}{|l|}
$1.9 \mathrm{E}-05$ \\
\end{tabular} & $A / C$ & 20.51208 & 0.19258 & Aspect ratio \\
\hline & & GLM & FDR (0.05) & 2 & 5159377 & \begin{tabular}{|l|}
$1.9 \mathrm{E}-05$ \\
\end{tabular} & $A / C$ & 20.51208 & 0.19258 & Roundness \\
\hline \multirow[t]{6}{*}{31} & \multirow{6}{*}{$\begin{array}{l}\text { solcap_snp_c2_436 } \\
0\end{array}$} & GLM & Bonferroni & 2 & 5356498 & $6.7 \mathrm{E}-07$ & $A / G$ & 28.68696 & 0.24585 & Aspect ratio \\
\hline & & GLM+Q & FDR (0.05) & 2 & 5356498 & $2.1 \mathrm{E}-05$ & $A / G$ & 20.2877 & 0.17924 & Aspect ratio \\
\hline & & $\begin{array}{l}\text { GLM+PC } \\
A\end{array}$ & Suggestive & 2 & 5356498 & $1.5 \mathrm{E}-05$ & $A / G$ & 21.20211 & 0.18928 & Aspect ratio \\
\hline & & GLM & Bonferroni & 2 & 5356498 & \begin{tabular}{|l|}
$6.7 \mathrm{E}-07$ \\
\end{tabular} & $A / G$ & 27.44411 & 0.23773 & Roundness \\
\hline & & $G L M+Q$ & FDR (0.05) & 2 & 5356498 & 9.6E-06 & $A / G$ & 22.18673 & 0.19441 & Roundness \\
\hline & & $\begin{array}{l}\text { GLM+PC } \\
A\end{array}$ & Suggestive & 2 & 5356498 & 1.5E-05 & $A / G$ & 21.20211 & 0.18928 & Roundness \\
\hline \multirow[t]{2}{*}{32} & \multirow{2}{*}{$\begin{array}{l}\text { solcap_snp_c2_571 } \\
90\end{array}$} & GLM & FDR (0.05) & 2 & 5394420 & 1.7E-05 & $\mathrm{A} / \mathrm{C}$ & 20.70086 & 0.19221 & Aspect ratio \\
\hline & & GLM & FDR (0.05) & 2 & 5394420 & $1.8 \mathrm{E}-05$ & $\mathrm{~A} / \mathrm{C}$ & 20.55906 & 0.19114 & Roundness \\
\hline \multirow[t]{2}{*}{33} & \multirow{2}{*}{$\begin{array}{l}\text { solcap_snp_c2_487 } \\
25\end{array}$} & GLM & FDR (0.05) & 2 & 5510774 & $2.2 \mathrm{E}-05$ & $\mathrm{~T} / \mathrm{C}$ & 20.07171 & 0.18573 & Aspect ratio \\
\hline & & GLM & FDR (0.05) & 2 & 5510774 & $2.5 \mathrm{E}-05$ & $\mathrm{~T} / \mathrm{C}$ & 19.85727 & 0.18411 & Roundness \\
\hline 34 & solcap_snp_c1_150 & GLM & FDR (0.05) & 2 & 5362501 & $2.4 \mathrm{E}-05$ & $\mathrm{~T} / \mathrm{C}$ & 19.91747 & 0.18629 & Aspect ratio \\
\hline
\end{tabular}




\begin{tabular}{|c|c|c|c|c|c|c|c|c|c|c|}
\hline & 3 & GLM & FDR (0.05) & 2 & 5362501 & $2.4 \mathrm{E}-05$ & $\mathrm{~T} / \mathrm{C}$ & 19.91934 & 0.1863 & Roundness \\
\hline \multirow[t]{2}{*}{35} & \multirow{2}{*}{$\begin{array}{l}\text { solcap_snp_c2_487 } \\
35\end{array}$} & GLM & FDR (0.05) & 2 & 5552679 & $2.4 \mathrm{E}-05$ & $A / G$ & 19.91747 & 0.18629 & Aspect ratio \\
\hline & & GLM & FDR (0.05) & 2 & 5552679 & \begin{tabular}{|l|}
$2.4 \mathrm{E}-05$ \\
\end{tabular} & $A / G$ & 19.91934 & 0.1863 & Roundness \\
\hline \multirow[t]{2}{*}{36} & \multirow{2}{*}{$\begin{array}{l}\text { solcap_snp_c1_375 } \\
0\end{array}$} & GLM & FDR (0.05) & 2 & 6090074 & $4.2 \mathrm{E}-06$ & $\mathrm{~T} / \mathrm{C}$ & 24.121 & 0.21707 & Aspect ratio \\
\hline & & GLM & FDR (0.05) & 2 & 6090074 & 9E-06 & $\mathrm{T} / \mathrm{C}$ & 22.27071 & 0.20381 & Roundness \\
\hline \multirow[t]{4}{*}{37} & \multirow{4}{*}{$\begin{array}{l}\text { solcap_snp_c1_164 } \\
05\end{array}$} & GLM & FDR (0.05) & 2 & 6707427 & $6.6 \mathrm{E}-06$ & $A / G$ & 23.03216 & 0.20932 & Aspect ratio \\
\hline & & $\begin{array}{l}\text { GLM+PC } \\
A\end{array}$ & Suggestive & 2 & 6707427 & 9.6E-05 & A/G & 16.83224 & 0.15409 & Aspect ratio \\
\hline & & GLM & FDR (0.05) & 2 & 6707427 & $6.6 \mathrm{E}-06$ & $A / G$ & 23.89646 & 0.21548 & Roundness \\
\hline & & $\begin{array}{l}\text { GLM+PC } \\
A\end{array}$ & Suggestive & 2 & 6707427 & $5 \mathrm{E}-05$ & $A / G$ & 18.34947 & 0.17054 & Roundness \\
\hline \multirow[t]{2}{*}{38} & \multirow{2}{*}{$\begin{array}{l}\text { solcap_snp_c1_374 } \\
6\end{array}$} & GLM & FDR (0.05) & 2 & 7050595 & $1.5 \mathrm{E}-05$ & $\mathrm{~T} / \mathrm{C}$ & 21.04094 & 0.19657 & Aspect ratio \\
\hline & & GLM & FDR (0.05) & 2 & 7050595 & $1.4 \mathrm{E}-05$ & $\mathrm{~T} / \mathrm{C}$ & 21.24232 & 0.19808 & Roundness \\
\hline \multirow[t]{5}{*}{39} & \multirow{5}{*}{$\begin{array}{l}\text { solcap_snp_c1_374 } \\
7\end{array}$} & GLM & Bonferroni & 2 & 7050714 & $1.9 \mathrm{E}-06$ & $\mathrm{~T} / \mathrm{C}$ & 26.12617 & 0.23301 & Aspect ratio \\
\hline & & GLM+Q & FDR (0.05) & 2 & 7050714 & 3.2E-05 & $\mathrm{T} / \mathrm{C}$ & 19.37954 & 0.17319 & Aspect ratio \\
\hline & & $\begin{array}{l}\mathrm{GLM}+\mathrm{PC} \\
\mathrm{A}\end{array}$ & Suggestive & 2 & 7050714 & 2.2E-05 & $\mathrm{T} / \mathrm{C}$ & 20.28852 & 0.17686 & Aspect ratio \\
\hline & & GLM & Bonferroni & 2 & 7050714 & $1.9 \mathrm{E}-06$ & $\mathrm{~T} / \mathrm{C}$ & 27.64594 & 0.24326 & Roundness \\
\hline & & GLM+Q & FDR (0.05) & 2 & 7050714 & 2.2E-05 & $\mathrm{T} / \mathrm{C}$ & 20.28477 & 0.17974 & Roundness \\
\hline
\end{tabular}




\begin{tabular}{|c|c|c|c|c|c|c|c|c|c|c|}
\hline & & $\begin{array}{l}\text { GLM+PC } \\
A\end{array}$ & Suggestive & 2 & 7050714 & $8.6 \mathrm{E}-06$ & $\mathrm{~T} / \mathrm{C}$ & 22.58985 & 0.19625 & Roundness \\
\hline \multirow[t]{6}{*}{40} & \multirow{6}{*}{$\begin{array}{l}\text { solcap_snp_c2_146 } \\
52\end{array}$} & GLM & Bonferroni & 2 & 8703476 & $1.7 \mathrm{E}-06$ & $A / G$ & 26.35701 & 0.23458 & Aspect ratio \\
\hline & & GLM+Q & FDR (0.05) & 2 & 8703476 & $5.1 \mathrm{E}-05$ & $A / G$ & 18.28407 & 0.16778 & Aspect ratio \\
\hline & & $\begin{array}{l}\text { GLM+PC } \\
A\end{array}$ & Suggestive & 2 & 8703476 & $6.5 \mathrm{E}-05$ & $A / G$ & 17.74889 & 0.16164 & Aspect ratio \\
\hline & & GLM & Bonferroni & 2 & 8703476 & 1.7E-06 & $A / G$ & 24.01768 & 0.21831 & Roundness \\
\hline & & GLM+Q & FDR (0.05) & 2 & 8703476 & $4.4 \mathrm{E}-05$ & $A / G$ & 18.62552 & 0.17228 & Roundness \\
\hline & & $\begin{array}{l}\text { GLM+PC } \\
A\end{array}$ & Suggestive & 2 & 8703476 & $4.4 \mathrm{E}-05$ & $A / G$ & 18.65739 & 0.17427 & Roundness \\
\hline \multirow[t]{6}{*}{41} & \multirow{6}{*}{$\begin{array}{l}\text { solcap_snp_c2_146 } \\
48\end{array}$} & GLM & Bonferroni & 2 & 8799527 & $1.4 \mathrm{E}-06$ & $\mathrm{~A} / \mathrm{C}$ & 27.01056 & 0.24553 & Aspect ratio \\
\hline & & $\mathrm{GLM}+\mathrm{Q}$ & FDR (0.05) & 2 & 8799527 & $4.9 \mathrm{E}-05$ & $\mathrm{~A} / \mathrm{C}$ & 18.45696 & 0.17279 & Aspect ratio \\
\hline & & $\begin{array}{l}\text { GLM+PC } \\
A\end{array}$ & Suggestive & 2 & 8799527 & $1 \mathrm{E}-04$ & $\mathrm{~A} / \mathrm{C}$ & 16.83119 & 0.15898 & Aspect ratio \\
\hline & & GLM & Bonferroni & 2 & 8799527 & $1.4 \mathrm{E}-06$ & $\mathrm{~A} / \mathrm{C}$ & 24.68137 & 0.22921 & Roundness \\
\hline & & GLM+Q & FDR (0.05) & 2 & 8799527 & $4.8 \mathrm{E}-05$ & $\mathrm{~A} / \mathrm{C}$ & 18.48983 & 0.17371 & Roundness \\
\hline & & $\begin{array}{l}\text { GLM+PC } \\
A\end{array}$ & Suggestive & 2 & 8799527 & $6.7 \mathrm{E}-05$ & $\mathrm{~A} / \mathrm{C}$ & 17.74091 & 0.17059 & Roundness \\
\hline \multirow[t]{2}{*}{42} & \multirow{2}{*}{$\begin{array}{l}\text { solcap_snp_c2_322 } \\
54\end{array}$} & GLM & FDR (0.05) & 2 & 13697523 & $4.9 \mathrm{E}-05$ & $A / G$ & 18.29319 & 0.1754 & Aspect ratio \\
\hline & & GLM & FDR (0.05) & 2 & 13697523 & $4.9 \mathrm{E}-05$ & $A / G$ & 18.82751 & 0.1796 & Roundness \\
\hline 43 & PotVar0022442 & GLM & FDR (0.05) & 7 & 1120011 & 7.4E-05 & $\mathrm{T} / \mathrm{C}$ & 17.33025 & 0.16772 & Aspect ratio \\
\hline
\end{tabular}




\begin{tabular}{|c|c|c|c|c|c|c|c|c|c|c|}
\hline & & GLM & FDR $(0.05)$ & 7 & 1120011 & 1.94E-04 & $\mathrm{T} / \mathrm{C}$ & 15.16808 & 0.14993 & Roundness \\
\hline \multirow[t]{2}{*}{44} & \multirow{2}{*}{$\begin{array}{l}\text { solcap_snp_c2_336 } \\
57\end{array}$} & GLM & FDR $(0.05)$ & 11 & 2274063 & $4.4 \mathrm{E}-05$ & $A / G$ & 18.55125 & 0.17744 & Aspect ratio \\
\hline & & GLM & FDR (0.05) & 11 & 2274063 & 4.00E-05 & $A / G$ & 18.75715 & 0.17905 & Roundness \\
\hline \multirow[t]{2}{*}{45} & \multirow{2}{*}{$\begin{array}{l}\text { solcap_snp_c1_150 } \\
4\end{array}$} & GLM & FDR (0.05) & 2 & 4479389 & $6.5 \mathrm{E}-06$ & $\mathrm{~A} / \mathrm{G}$ & 23.10075 & 0.21174 & Aspect ratio \\
\hline & & GLM & FDR $(0.05)$ & 2 & 4479389 & $1.36 \mathrm{E}-05$ & $A / G$ & 21.29554 & 0.19848 & Roundness \\
\hline \multirow[t]{3}{*}{46} & \multirow{3}{*}{$\begin{array}{l}\text { solcap_snp_c2_508 } \\
24\end{array}$} & GLM+Q & FDR (0.05) & 12 & 54479773 & $2.7 \mathrm{E}-05$ & $\mathrm{~T} / \mathrm{C}$ & 20.01852 & 0.18645 & Aspect ratio \\
\hline & & $\mathrm{GLM}+\mathrm{Q}$ & FDR (0.05) & 12 & 54479773 & $6.56 \mathrm{E}-05$ & $\mathrm{~T} / \mathrm{C}$ & 17.88054 & 0.17686 & Circularity \\
\hline & & GLM+Q & FDR (0.05) & 12 & 54479773 & $2.78 \mathrm{E}-04$ & $\mathrm{~T} / \mathrm{C}$ & 14.54952 & 0.14453 & Roundness \\
\hline \multirow[t]{2}{*}{47} & \multirow{2}{*}{$\begin{array}{l}\text { solcap_snp_c2_548 } \\
15\end{array}$} & $\mathrm{GLM}+\mathrm{Q}$ & FDR (0.05) & 1 & 1125639 & $9.1 \mathrm{E}-05$ & $A / G$ & 16.98376 & 0.16372 & Aspect ratio \\
\hline & & $\mathrm{GLM}+\mathrm{Q}$ & FDR (0.05) & 1 & 1125639 & $6.3 \mathrm{E}-05$ & $A / G$ & 17.82237 & 0.17128 & Roundness \\
\hline \multirow[t]{4}{*}{48} & \multirow[t]{4}{*}{$\begin{array}{l}\text { solcap_snp_c1_154 } \\
62\end{array}$} & GLM+Q & Bonferroni & 7 & 205949 & $1.3 \mathrm{E}-06$ & $A / G$ & 27.20638 & 0.23095 & $\begin{array}{l}\text { 1st bi- } \\
\text { component }\end{array}$ \\
\hline & & $\begin{array}{l}\text { GLM+PC } \\
A\end{array}$ & Suggestive & 7 & 205949 & $1.3 \mathrm{E}-05$ & $A / G$ & 21.51624 & 0.17525 & $\begin{array}{l}\text { 1st bi- } \\
\text { component }\end{array}$ \\
\hline & & $\mathrm{GLM}+\mathrm{Q}$ & FDR $(0.05)$ & 7 & 205949 & $5.6 \mathrm{E}-06$ & $A / G$ & 23.5453 & 0.20251 & Circularity \\
\hline & & $\begin{array}{l}\text { GLM+PC } \\
\text { A }\end{array}$ & Suggestive & 7 & 205949 & $5 \mathrm{E}-05$ & $A / G$ & 18.37838 & 0.1726 & Circularity \\
\hline 49 & PotVar0047235 & $\begin{array}{l}\text { GLM+PC } \\
\text { A }\end{array}$ & FDR (0.05) & 11 & 39417958 & $5.7 \mathrm{E}-06$ & $\mathrm{~T} / \mathrm{C}$ & 23.51133 & 0.20444 & Circularity \\
\hline
\end{tabular}




\begin{tabular}{|c|c|c|c|c|c|c|c|c|c|c|}
\hline \multirow[t]{2}{*}{50} & \multirow[t]{2}{*}{$\begin{array}{l}\text { solcap_snp_c2_520 } \\
67\end{array}$} & GLM & $\begin{array}{l}\text { Suggestive } \\
\text { Suggestive }\end{array}$ & 5 & 1847556 & $3.7 \mathrm{E}-05$ & $A / G$ & 18.89164 & 0.17674 & $\begin{array}{l}\text { 1st bi- } \\
\text { component }\end{array}$ \\
\hline & & $\mathrm{GLM}+\mathrm{Q}$ & FDR (0.05) & 5 & 1847556 & $8.8 \mathrm{E}-05$ & $A / G$ & 16.97574 & 0.15589 & $\begin{array}{l}\text { 1st bi- } \\
\text { component }\end{array}$ \\
\hline \multirow[t]{2}{*}{51} & \multirow[t]{2}{*}{ PotVar0097020 } & GLM+Q & FDR (0.05) & 9 & 60563436 & $4.3 \mathrm{E}-06$ & $T / G$ & 24.1761 & 0.21034 & $\begin{array}{l}\text { 1st bi- } \\
\text { component }\end{array}$ \\
\hline & & $\begin{array}{l}\text { GLM+PC } \\
\text { A }\end{array}$ & Suggestive & 9 & 60563436 & $1.8 \mathrm{E}-05$ & $T / G$ & 20.69739 & 0.1683 & $\begin{array}{l}\text { 1st bi- } \\
\text { component }\end{array}$ \\
\hline \multirow[t]{2}{*}{52} & \multirow[t]{2}{*}{ PotVar0097065 } & GLM+Q & Bonferroni & 9 & 60565011 & $2.8 \mathrm{E}-06$ & $\mathrm{~T} / \mathrm{C}$ & 25.31005 & 0.22143 & $\begin{array}{l}\text { 1st bi- } \\
\text { component }\end{array}$ \\
\hline & & $\begin{array}{l}\text { GLM+PC } \\
A\end{array}$ & Suggestive & 9 & 60565011 & $2.6 \mathrm{E}-05$ & $T / G$ & 19.92614 & 0.16731 & $\begin{array}{l}\text { 1st bi- } \\
\text { component }\end{array}$ \\
\hline 53 & PotVar0052560 & GLM & Suggestive & 12 & 59793471 & $6.3 \mathrm{E}-05$ & $A / G$ & $17.68548 \mathrm{~A}$ & 0.16894 & $\begin{array}{l}\text { 1st bi- } \\
\text { component }\end{array}$ \\
\hline
\end{tabular}


Figure 1

Manhattan plots for "Preparative tuber starch yield" trait, A) GLM B) GLM+PCA C) GLM+Q. 

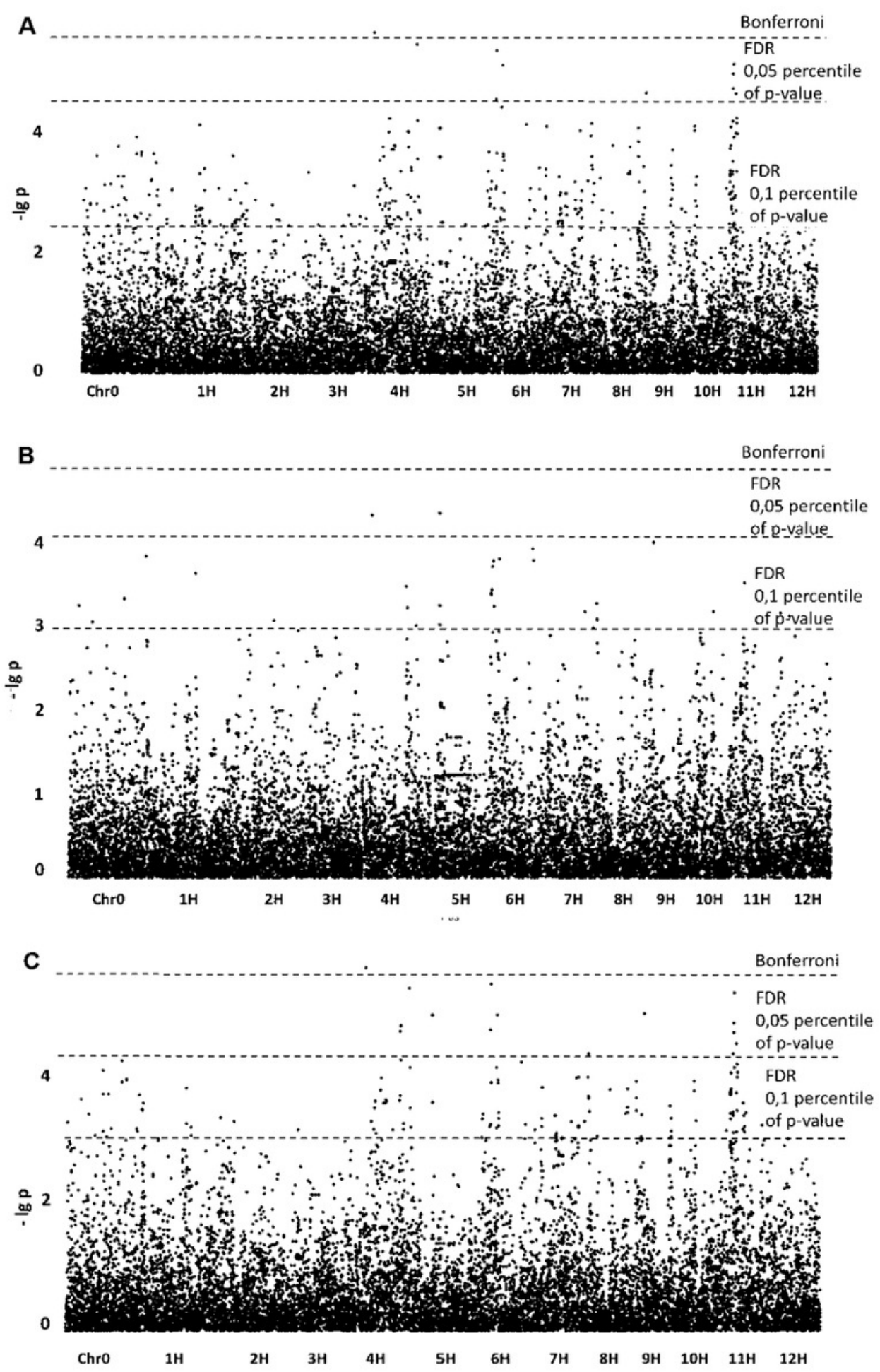
Figure 2

Manhattan plots for «Aspect Ratio» trait. A) GLM; B) GLM+PCA; C) GLM+Q. 

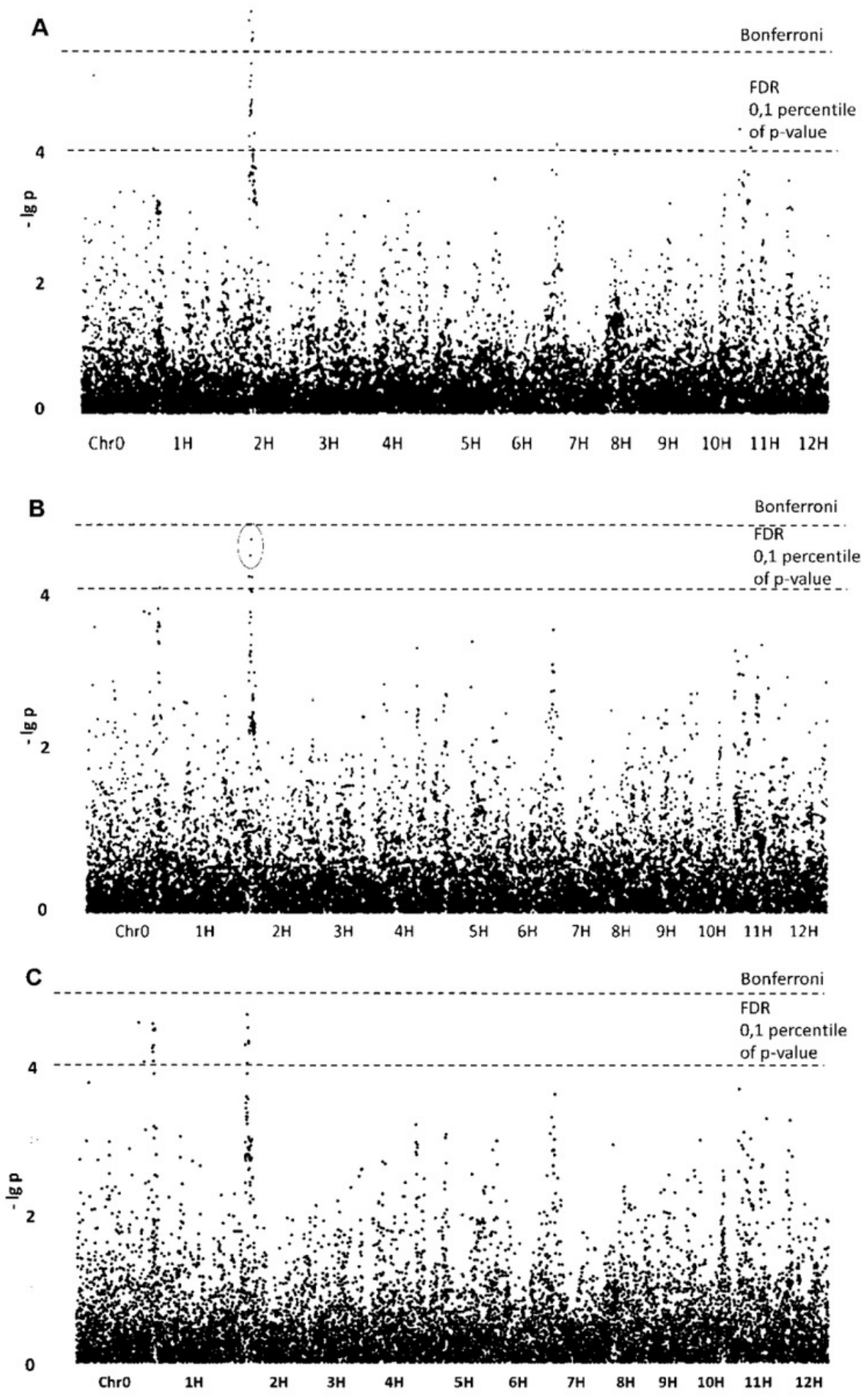